\section{(1) \\ CrossMark}

\title{
Prevalence, risk factors and clinical correlates of COPD in a rural setting in Tanzania
}

\author{
Ng'weina Francis Magitta (1) ${ }^{1,2}$, Richard William Walker ${ }^{3,4}$, Komalkirti \\ Keshavkiran Apte ${ }^{5}$, Meshack Denson Shimwela ${ }^{6}$, Julius David Mwaiselage ${ }^{7}$, \\ Anna Alphonce Sanga ${ }^{1,6}$, Anil Kumar Namdeo ${ }^{8}$, Sapna Jitendra Madas ${ }^{5}$ and \\ Sundeep Santosh Salvi ${ }^{5}$
}

Affiliations: ${ }^{1}$ Non-Communicable Diseases Research Group, Ifakara Health Institute, Dar es Salaam, Tanzania. ${ }^{2}$ Dept of Biochemistry, School of Health Sciences, University of Dar es Salaam, Dar es Salaam, Tanzania. ${ }^{3}$ Dept of Medicine, Northumbria Healthcare NHS Foundation Trust, North Tyneside General Hospital, Newcastle upon Tyne, UK. ${ }^{4}$ Institute of Health and Society, Newcastle University, Newcastle upon Tyne, UK. ${ }^{5}$ Chest Research Foundation, Pune, India. ${ }^{6}$ Amana Regional Referral Hospital, Dar es Salaam, Tanzania. ${ }^{7}$ Dept of Clinical Oncology, Muhimbili University of Health and Allied Sciences, Dar es Salaam, Tanzania. ${ }^{8}$ Transport Operations Research Group, School of Civil Engineering and Geosciences, Newcastle University, Newcastle upon Tyne, UK.

Correspondence: Ng'weina Francis Magitta, Ifakara Health Institute, P0 Box 78373, Plot 463, Kiko Avenue, Mikocheni, Dar es Salaam, Tanzania. E-mail: nmagittadihi.or.tz

@ERSpublications

The burden of COPD is high in Tanzania: indoor air pollution resulting from biomass smoke is a major risk factor http://ow.ly/wk2x30gEgQN

Cite this article as: Magitta NF, Walker RW, Apte KK, et al. Prevalence, risk factors and clinical correlates of COPD in a rural setting in Tanzania. Eur Respir J 2018; 51: 1700182 [https://doi.org/10.1183/ 13993003.00182-2017].

ABSTRACT Chronic obstructive pulmonary disease (COPD) causes substantial burden of disease in developed countries, but there are limited data from Africa. We aimed to estimate the prevalence of COPD in Tanzania and identify the risk factors associated with it.

This was a cross-sectional descriptive survey involving adults aged $\geqslant 35$ years. We collected data on symptoms and risk factors using the Burden of Obstructive Lung Diseases questionnaire. Spirometry was performed and COPD diagnosed based on post-bronchodilator forced expiratory volume in $1 \mathrm{~s} /$ forced vital capacity $<70 \%$. We also measured indoor and outdoor carbon monoxide (CO) levels.

A total of 869 participants $(49.1 \%$ females $)$ completed the questionnaires. Of these, $57.1 \%$ completed post-bronchodilator spirometry. Of the $25.2 \%$ ever-smokers, only $5.4 \%$ were current smokers. COPD prevalence was estimated at $17.5 \%$ (21.7\% in males and $12.9 \%$ in females). COPD was associated with a history of cough, phlegm production and wheezing. $51.7 \%$ of COPD patients reported cough and $85 \%$ had mild to moderate airway limitation. Females had a higher rate of exacerbation. Pulmonary tuberculosis (TB) was reported in $10 \%$ of patients. Only $1.7 \%$ of patients who were diagnosed as COPD had ever received any medication, with only one female COPD patient having received an inhaler. $99.5 \%$ of the population used biomass fuels for cooking. The majority of households had CO levels up to $20 \mathrm{ppm}$.

The prevalence of COPD in Tanzania is high, with a peak at a relatively young age and a preponderance in males. A history of TB, cigarette smoking and male sex are important risk factors. Indoor air pollution coupled with use of biomass fuel for cooking and heating may be an important risk factor for developing COPD in rural Tanzania. However, these factors need to be studied further. 


\section{Introduction}

Chronic obstructive pulmonary disease (COPD) is an important cause of morbidity and mortality in developed countries. COPD is the third leading cause of death globally and among the top five leading causes of disability-adjusted life-years [1]. In Africa, there is limited information on the epidemiology and clinical correlates of COPD. A recent study from Uganda reported a COPD prevalence of 16\%, with $40 \%$ of patients aged $<40$ years [2]. The rising trend of important risk factors such as tobacco smoking, poverty, poor education and exposure to household air pollution in Africa is likely to significantly increase the burden of COPD $[3,4]$.

The hallmark of COPD is a poorly reversible and progressive airflow limitation resulting from prolonged exposure to inhalational noxious pulmonary agents that initiates detrimental chronic airway inflammation and lung damage [5-7]. Cigarette smoking is the major cause of COPD worldwide. However, in developing countries exposure to air pollution responsible for non-tobacco-smoking COPD might predominate [8-13]. Recent studies have described non-tobacco-smoking COPD due to indoor pollution resulting from the use of biomass fuel and open fires for domestic purposes in poorly ventilated households $[12,14]$. This observation has a substantial impact on COPD in rural communities, particularly among females and their young children who are routinely engaged in cooking activities [15]. In Tanzania, most rural communities in the malarial endemic regions often burn mosquito coils or make other forms of smoke as a means to repel mosquitoes at night, thus increasing indoor pollution. The burning of mosquito coils produces higher levels of indoor air pollution than the burning of biomass fuel for cooking purposes [16].

Patients with COPD generally present with chronic cough and sputum production with or without dyspnoea. This clinical presentation tends to be ignored by patients until they present late for treatment at advanced stages of disease, often after developing intolerable dyspnoea. In Africa, these patients might frequently be misdiagnosed and treated for pulmonary tuberculosis (TB) or heart failure. Moreover, the lack of expertise and diagnostic tools such as spirometers are major bottlenecks for the proper diagnosis and treatment of patients with COPD [4]. The current Global Initiative for Chronic Obstructive Lung Disease (GOLD) criteria for the management of COPD requires stepwise administration of bronchodilators and steroids, preferably via inhalational routes, during stable states and exacerbations $[17,18]$. However, in Africa, for various reasons these guidelines are often not adhered to in routine clinical practice [19]. For instance, there is continued use of inappropriate drugs in the management of COPD and most drugs are frequently administered through routes other than the recommended inhalational route, thus exposing patients to adverse effects, reduced efficacy, frequent exacerbations and poor health-related quality of life [20, 21].

In the current study, we explored the burden of COPD in Tanzania together with the associated risk factors and drivers for disease control.

\section{Methods}

\section{Study design and population}

We conducted a population-based cross-sectional descriptive study in Maswa district in Simiyu region, Tanzania. The villagers are predominantly farmers growing regular food crops as well as cash crops, mainly cotton and tobacco. In addition to farming, livestock keeping is a major activity. Moreover, mining (gold, diamond and nickel) is also a major activity in the region.

We assessed the burden and determinants of COPD using the Burden of Obstructive Lung Diseases (BOLD) protocol (www.boldstudy.org) for participants aged $\geqslant 35$ years who were randomly selected. Males and females aged $\geqslant 35$ years and resident in the study area for $\geqslant 6$ months were eligible to participate in the study. Additionally, the individual must not have had a current history of mental illness or active pulmonary TB and must not have had any contraindication to performing spirometry (e.g. history of any cerebral, ophthalmic, thoracic or abdominal surgery in the last 1 month, or severe heart disease, current respiratory infection, past history of pneumothorax, emboli or aneurysms). The interviewers administered a set of BOLD validated questionnaires to all eligible participants who consented. In addition, participants underwent spirometry testing using a 3-L daily calibrated NDD EasyOne spirometer (NDDmed, Andover, MA, USA). The study was preceded by conducting community sensitisation meetings with the local authority and key informants at the selected study sites. The study was approved by the Tanzania National Institute for Medical Research.

Received: Jan 252017 | Accepted after revision: Nov 062017

Support statement: This work was supported through funds obtained from GlaxoSmithKline Ltd through the Trust in Science-Africa initiative. Funding information for this article has been deposited with the Crossref Funder Registry.

Conflict of interest: None declared. 


\section{Sampling and sample size estimation}

Maswa district consists of a predominantly rural population of over 400000 who live in over 50000 households. The district is organised into three divisions, i.e. Mwagala, Nunghu and Sengerema. These divisions have a total of 36 wards which cover 104 villages. We selected two wards randomly, i.e. Lalago and Mbaragane, from the 15 Mwagala division wards. We further randomly selected three villages from each of the two wards, i.e. Gala (population 2870), Lalago (population 8326) and Mwakidiga (population 3700) from the Lalago ward, and Sulu (population 4520), Mbaragane (population 5197) and Mandang'ombe (3357) from the Mbaragane ward. The total population consisted of 4430 households that housed a population of 27970 . All these households were visited. Based on our inclusion criteria, $70.0 \%$ (19579) of the population were not eligible to participate as they were $<35$ years of age, $4.8 \%$ (1345) were not resident in these villages for $>6$ months, $0.3 \%$ (78) had some form of mental illness, 3.0\% (826) had active TB, 6.9\% (1956) had contraindications for performing spirometry and $0.4 \%$ (114) refused to participate. In each visited household, eligible participants who consented to the study were recruited. $11.5 \%(n=3203)$ of the eligible participants were not available when our field workers visited their household. For individuals who did not agree to participate in the study, we completed a minimal data and refusal questionnaire that contained information on age, sex, diagnosis of COPD and history of cigarette smoking. As this study is based on the BOLD study, the minimum sample size required was 600 individuals ( 300 males and 300 females) aged $\geqslant 40$ years with an expected prevalence of $12 \%$. A study by FulLERTON et al. [22] conducted in Malawi reported a COPD prevalence of 16\%. The prevalence of COPD in Africa is therefore estimated to be at least $12 \%$ (if not more) and hence we aimed at a sample size of at least 600 .

\section{Data collection}

We collected information about respiratory symptoms, exposure to potential risk factors, occupation, respiratory diagnoses, comorbidities, healthcare utilisation, medication use, activity limitation and health status. Smoking status was categorised as never-smoker, ex-smoker and current smoker. An ex-smoker was defined as a person who quit smoking $\geqslant 3$ months ago. Biomass fuel use was categorised under various forms of biomass fuel used, e.g. charcoal, coal, coke, wood, dung and crop residues. Exposure to biomass fuel was quantified as number of hours of biomass smoke exposure per day and the number of years of biomass smoke exposure. All consenting participants were evaluated for airflow limitation with spirometry, which was repeated 15-20 min after inhalation of $200 \mu \mathrm{g}$ of salbutamol administered via a spacer. The spirometry measurements used for analysis included forced vital capacity (FVC), forced expiratory volume in $1 \mathrm{~s}\left(\mathrm{FEV}_{1}\right)$ and total expiratory time. In addition, all basic demographic data and personal particulars were collected together with information on clinical severity and control of COPD. The diagnosis of COPD was based on the presence of airflow limitation that was not fully reversible, based on post-bronchodilator $\mathrm{FEV}_{1} / \mathrm{FVC}<70 \%$, with or without the presence of symptoms. Exacerbations were defined as episodes where the individual had to be admitted to a hospital for medical care in the past 12 months. We also measured blood pressure, pulse rate and carried out standard anthropometry measurements.

\section{Pollution monitoring}

We selected households for measuring indoor air pollution levels using Langan T15x monitors (Langan, San Francisco, CA, USA) based on carbon monoxide (CO) monitoring with a sampling rate of 1 min. The sites for pollution monitoring were randomly determined based on the spatial configuration of the area to capture $>95 \%$ of the area. A list of houses surrounding each selected site was made and each house approached based on their distance from the optimal site. Due to financial and logistical constraints, one house was recruited from each of these sites for intensive outdoor and indoor pollution monitoring. 42 households were selected for monitoring of indoor pollution levels. In parallel, a similar number of outdoor pollution levels were monitored in residential settings.

\section{Statistical analysis}

The collected data were initially entered on paper questionnaires and later entered into Epi Info software (Centers for Disease Control and Prevention, Atlanta, GA, USA) via double data entry before being exported for analysis in SPSS Statistics (IBM, Armonk, NY, USA). We used the Chi-squared test to detect differences in the frequencies of categorical characteristics. We used the t-test to detect differences in the mean values between the groups. Respiratory symptoms, biomass fuel use, cigarette smoking, occupation and demographic variables were tested for associations. The smoking dependency was assessed using the Fagerstrom score. Scores of $1-2,3-4,5-7$ and $\geqslant 8$ were considered to represent low, low-to-moderate, moderate and high nicotine dependence, respectively. Population-attributable risk was used to assess the contribution of smoking in the risk of COPD. The prevalence of COPD among the smokers and nonsmokers was studied. A confidence interval of $95 \%$ was used to estimate the relative and attributable 


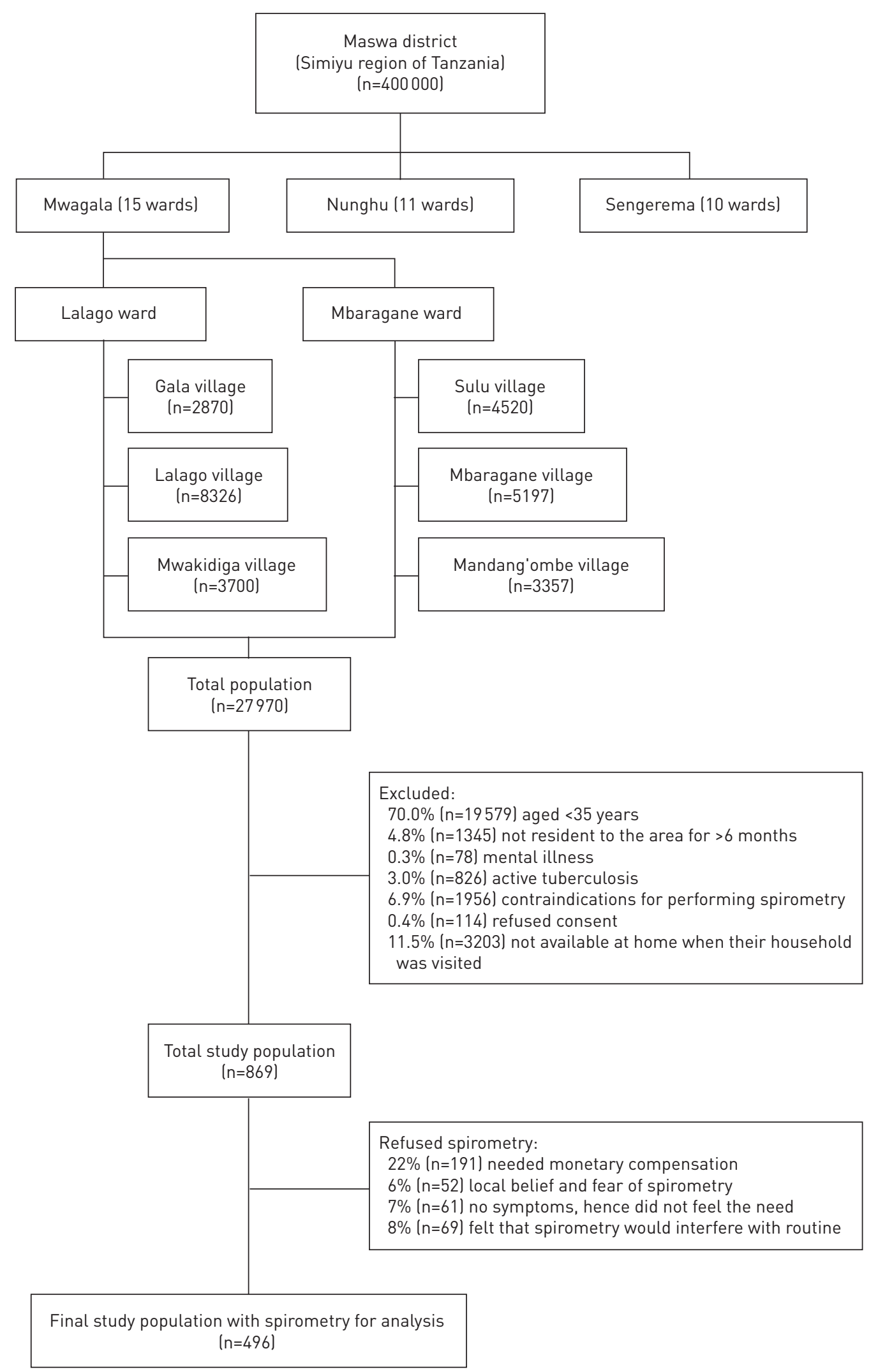

FIGURE 1 Flowchart of study population selection. 
risks. Relative risk was calculated as the proportion of COPD patients who were ever-smokers versus the COPD patients who were nonsmokers. The attributable risk was calculated as the difference between the COPD prevalence among the ever-smokers and the COPD prevalence among the nonsmokers. The population-attributable risk was calculated as the difference between the COPD prevalence in the ever-smokers and the COPD prevalence in the total study population. The population-attributable risk percentage was the proportion of the difference in COPD prevalence in the ever-smokers and the total population and the COPD prevalence in ever-smokers expressed as a percentage. The relationships between COPD and associated risk factors were analysed using the Chi-squared test and multiple logistic regressions to calculate odds ratios. A p-value of $<0.05$ was considered to be indicative of statistical significance.

\section{Results}

\section{Demographic characteristics}

Of the eligible participants, a total of 869 participants (427 females (49.1\%)) consented and completed the questionnaires (figure 1). Of all respondents, 57.1\% (496 out of 869) underwent post-bronchodilator spirometry, of which $53 \%$ were male. Over $98 \%$ of the spirometry efforts were acceptable. Mean \pm SD age of the study population was $51.8 \pm 10.6$ years. $25.2 \%$ (125 out of 496 ) of the respondents were either ex- or current smokers. 13 out of the 125 ever-smokers were female. The majority of the respondents had a primary level of education and normal nutritional status. $99.5 \%$ of the study population used biomass fuel for cooking and heating purposes. $96.4 \%$ of the population worked as farmers (table 1).

\begin{tabular}{|c|c|}
\hline Subjects & 496 \\
\hline \multicolumn{2}{|l|}{ Sex } \\
\hline Male & $263(53.0)$ \\
\hline Female & $233(47.0)$ \\
\hline \multicolumn{2}{|l|}{ Age years } \\
\hline $30-40$ & $23(4.6)$ \\
\hline $41-50$ & $236(47.7)$ \\
\hline $51-60$ & $134(27.1)$ \\
\hline$>60$ & $102(20.6)$ \\
\hline \multicolumn{2}{|l|}{ Educational level } \\
\hline Primary education & 295 (59.5) \\
\hline Secondary education & $28(5.6)$ \\
\hline Other $\#$ & $10(0.2)$ \\
\hline No formal education & $163(32.9)$ \\
\hline \multicolumn{2}{|l|}{ BMI $\mathrm{kg} \cdot \mathrm{m}^{-2}$} \\
\hline$<18.5$ (underweight) & $61(12.3)$ \\
\hline 18.5-24.9 (normal weight) & $321(64.8)$ \\
\hline 25.0-29.9 (overweight) & $76(15.4)$ \\
\hline$\geqslant 30.0$ (obese) & $37(7.5)$ \\
\hline \multicolumn{2}{|l|}{ Smoking status } \\
\hline Never-smoker & 371 (male: 151) (74.8) \\
\hline Ex-smoker & 98 (male: 91) (19.8) \\
\hline Current smoker & 27 (male: 21) (5.4) \\
\hline \multicolumn{2}{|l|}{ Occupation } \\
\hline Farming & $842(96.9)$ \\
\hline Construction & $27(3.1)$ \\
\hline \multicolumn{2}{|l|}{ Fuel used } \\
\hline Wood & 803 (92.4) \\
\hline Charcoal & $130(14.9)$ \\
\hline Crop residues & $13(1.5)$ \\
\hline Animal dung & $5(0.6)$ \\
\hline Liquefied petroleum gas & $3(0.4)$ \\
\hline Kerosene & $1(0.1)$ \\
\hline Electricity & $1(0.1)$ \\
\hline
\end{tabular}

Data are presented as $\mathrm{n}$ or $\mathrm{n}(\%)$. BMI: body mass index. ${ }^{\text {\# }}$ : high school, 4 years of college or vocational training education; ${ }^{\text {? }}$ : multiple forms of fuel used for cooking and heating within the same household. 
TABLE 2 Age and sex distribution of chronic obstructive pulmonary disease (COPD) according to Global Initiative for Chronic Obstructive Lung Disease-defined criteria for airflow limitation

\begin{tabular}{|c|c|c|c|c|c|}
\hline & \multicolumn{4}{|c|}{ COPD } & \multirow[t]{2}{*}{ Total } \\
\hline & Mild & Moderate & Severe & Very severe & \\
\hline \multicolumn{6}{|c|}{ Age $30-40$ years } \\
\hline Male & $0(0)$ & $0(0)$ & $0(0.00)$ & $0(0.0)$ & 0 \\
\hline Female & $1(33)$ & $2(67)$ & $0(0.00)$ & $0(0.0)$ & 3 \\
\hline Total & $1(33)$ & $2(67)$ & $0(0.00)$ & $0(0.0)$ & 3 \\
\hline \multicolumn{6}{|c|}{ Age $41-50$ years } \\
\hline Male & $3(33)$ & $5(56)$ & $1(11.1)$ & $0(0.0)$ & 9 \\
\hline Female & $2(29)$ & $5(71)$ & $0(0.00)$ & $0(0.0)$ & 7 \\
\hline Total & $5(31)$ & $10(63)$ & $1(6.3)$ & $0(0.0)$ & 16 \\
\hline \multicolumn{6}{|c|}{ Age $51-60$ years } \\
\hline Male & $5(33)$ & $6(40)$ & 2 (13.3) & 2 (13.3) & 15 \\
\hline Female & $2(20)$ & $5(50)$ & $3(30.0)$ & $0(0.0)$ & 10 \\
\hline Total & $7(28)$ & $11(44)$ & $5(20.0)$ & $2(8.0)$ & 25 \\
\hline \multicolumn{6}{|c|}{ Age $>60$ years } \\
\hline Male & $17(52)$ & $12(36)$ & $4(12.1)$ & $0(0.0)$ & 33 \\
\hline Female & $3(30)$ & $6(60)$ & $1(10.0)$ & $0(0.0)$ & 10 \\
\hline Total & $20(47)$ & $18(42)$ & $5(11.6)$ & $0(0.0)$ & 43 \\
\hline \multicolumn{6}{|l|}{ Total } \\
\hline Male & $25(44)$ & $23(40)$ & 7 (12.3) & $2(3.5)$ & 57 \\
\hline Female & $8(27)$ & $18(60)$ & 4 (13.3) & $0(0.0)$ & 30 \\
\hline Total & 33 (38) & $41(47)$ & $11(12.6)$ & $2(2.3)$ & 87 \\
\hline
\end{tabular}

Data are presented as $\mathrm{n}(\%)$ or $\mathrm{n}$.

\section{COPD prevalence and risk factors}

None of the study participants had a previous diagnosis of COPD. The overall prevalence of COPD was reported using post-bronchodilator $\mathrm{FEV}_{1} / \mathrm{FVC}<70 \%$, but we also used a definition based on post-bronchodilator FEV1/FVC <lower limit of normal (LLN) and age-dependent criteria: 1) age $<40$ years, post-bronchodilator $\mathrm{FEV} 1 / \mathrm{FVC}<75 \%$, 2) age $40-60$ years, post-bronchodilator $\mathrm{FEV} 1 / \mathrm{FVC}<70 \%$ and 3 ) age $>60$ years, post-bronchodilator $\mathrm{FEV} 1 / \mathrm{FVC}<65 \%$. The overall prevalence rates based on these three criteria were $17.5 \%, 11.1 \%$ and $14.9 \%$, respectively. Furthermore, it was shown that males were more affected than females (OR 1.87, 95\% CI 1.2-3.03; p=0.01) (tables 2 and 3). The trend of the prevalence of COPD showed a direct proportional relationship with age. The risk of COPD increases 4-fold (OR 4.02, 95\% CI 1.1-14.7; $\mathrm{p}=0.016$ ), 9-fold (OR 9.4, 95\% CI 4.8-18.3; $\mathrm{p}<0.0001$ ) and 3-fold (OR 3.2, 95\% CI 1.75.8; $\mathrm{p}<0.0001$ ) with increasing age of $40-50,50-60$ and $>60$ years, respectively (table 3 ). $10 \%$ (three out of 30 ) of females developed COPD at age $<40$ years based on post-bronchodilator $\mathrm{FEV} 1 / \mathrm{FVC}<70 \%$ and this



Data are presented as $\mathrm{n}$ or $\mathrm{n}(\%)$, unless otherwise stated. ${ }^{\#}$ : as $99.5 \%$ of the study population used biomass for cooking and heating purposes and $94 \%$ of the population was engaged in farming as their occupation, no associations could be calculated with use of biomass and occupation. $p<0.05$ was considered to be indicative of statistical significance. 


\begin{tabular}{|c|c|c|c|c|c|}
\hline Variable & Dependency & Subjects $\mathrm{n}$ & Mean \pm SD & $\begin{array}{c}\text { Mean difference } \\
(95 \% \mathrm{CI})\end{array}$ & p-value \\
\hline Age years & $\begin{array}{c}\text { Low-to-moderate } \\
\text { Significant }\end{array}$ & $\begin{array}{l}7 \\
5\end{array}$ & $\begin{array}{c}57.31 \pm 8.15 \\
50.63 \pm 11.96\end{array}$ & $6.67(-6.18-19.53)$ & 0.274 \\
\hline Cigarette smoking years & $\begin{array}{l}\text { Low-to-moderate } \\
\text { Significant }\end{array}$ & $\begin{array}{l}7 \\
5\end{array}$ & $\begin{array}{c}37.7 \pm 7.94 \\
24.43 \pm 4.83\end{array}$ & $12.64(3.68-21.6)$ & 0.01 \\
\hline Pack-years & $\begin{array}{c}\text { Low-to-moderate } \\
\text { Significant }\end{array}$ & $\begin{array}{l}7 \\
5\end{array}$ & $\begin{array}{c}11.69 \pm 11.84 \\
8.54 \pm 4.88\end{array}$ & $3.16(-9.46-15.78)$ & 0.589 \\
\hline
\end{tabular}

\#: only 12 of the 27 current smokers provided data on nicotine dependence.

figure was even higher when using other diagnostic criteria. Of the 27 smokers, only 12 smokers provided data on the nicotine dependency questionnaire and showed significant dependency based on the Fagerstrom score, which was significantly associated with the number of years of smoking $(p=0.01)$ (table 4). Cigarette smoking had a population-attributable risk of $17.02 \%$ and $14.92 \%$ on the prevalence of COPD based on post-bronchodilator $\mathrm{FEV} 1 / \mathrm{FVC}<70 \%$ and $\mathrm{FEV} 1 / \mathrm{FVC}<\mathrm{LLN}$ diagnostic criteria for COPD, respectively. $99.5 \%$ of participants were found to have exposure to biomass fuel with comparable exposure status between COPD patients and non-COPD participants. $92.4 \%$ used wood, $14.9 \%$ used charcoal, $1.5 \%$ used crop residues and $0.6 \%$ used animal dung, while $0.3 \%$ used liquefied petroleum gas, $0.1 \%$ used electricity and $0.1 \%$ used kerosene for cooking and heating purposes (table 1 ). We did not have sufficient power to study the risk of biomass fuel smoke exposure for COPD as $99.5 \%$ of the total population was skewed towards the use of biomass fuel. Hence, no definitive association could be established. A past history of TB was significantly associated with COPD (OR 5.93, 95\% CI 2.05-17.18; $\mathrm{p}<0.001)$. The population-attributable risk for smoking in our population was $17.02 \%$.

COPD clinical presentation, medication use, disease control and comorbidity

$51.7 \%$ of the patients with COPD presented with cough as the main respiratory symptom (table 5). About $85 \%$ of both male and female patients with COPD had mild to moderate airway limitation as stratified under the GOLD classification (table 2). The severity of COPD was significantly associated with cough $(\mathrm{p}=0.025)$, phlegm $(\mathrm{p}=0.028)$ and wheezing $(\mathrm{p}=0.002)$. Furthermore, the results revealed increased activity limitation in COPD patients with moderate to severe forms. COPD patients were found to have more

TABLE 5 Respiratory symptoms, spirometry indices and rate of exacerbations in the total study population compared with chronic obstructive pulmonary disease (COPD) patients

\begin{tabular}{|c|c|c|}
\hline Clinical characteristics & $\begin{array}{l}\text { Total study } \\
\text { population }\end{array}$ & $\begin{array}{l}\text { COPD } \\
\text { patients }\end{array}$ \\
\hline Subjects & 869 & 87 \\
\hline \multicolumn{3}{|l|}{ Respiratory symptoms } \\
\hline Cough & $387(44.5)$ & $45(51.7)$ \\
\hline Phlegm & $290(33.4)$ & $31(35.6)$ \\
\hline Wheeze & $163(18.8)$ & $28(32.2)$ \\
\hline Shortness of breath & $64(7.4)$ & $13(14.9)$ \\
\hline $\begin{array}{l}\text { Presence of respiratory symptoms which led to limitation of activity } \\
\text { or work absenteeism }\end{array}$ & 65 (male: 27) & 14 (male: 8) \\
\hline \multicolumn{3}{|l|}{ Frequency of exacerbations in the past 12 months } \\
\hline 0 & 11 (male: 8) & 2 (male: 2) \\
\hline 1 & 5 (male: 2) & 1 (male: 0 ) \\
\hline 2 & 5 (male: 2) & 1 (male: 1) \\
\hline$\geqslant 3$ & 44 (male: 15) & 10 (male: 5) \\
\hline \multicolumn{3}{|l|}{ Post-test spirometry measurements } \\
\hline FVC \% pred & $97.3 \pm 15.7$ & $96.3 \pm 20.2$ \\
\hline FEV $1 \%$ pred & $90.4 \pm 17.7$ & $72.4 \pm 20.2$ \\
\hline
\end{tabular}

Data are presented as $\mathrm{n}, \mathrm{n}(\%)$ or mean \pm SD. FVC: forced vital capacity; FEV1: forced expiratory volume in $1 \mathrm{~s} .{ }^{\#}: \mathrm{n}=469$ total study population and $\mathrm{n}=87$ COPD patients. 
symptoms of wheeze and shortness of breath than those who did not have COPD based on spirometry (figure 2). Those individuals without airflow obstruction on spirometry were also found to have substantial levels of respiratory symptoms, which could be explained by the high use of biomass fuel in the study population. $14.0 \%$ of male COPD patients and $20.0 \%$ of female COPD patients had a major limitation of activity that led to work absenteeism. $16.7 \%$ of the female COPD patients were found to have had three or more exacerbations requiring hospitalisation in the past 12 months, whereas only $8.8 \%$ of the male COPD patients had three or more exacerbations requiring hospitalisation in the past 12 months.

We also assessed for associations of COPD with heart disease, heart failure, hypertension, diabetes, lung cancer, stroke and pulmonary TB among all responders. The only significant comorbidity associated with COPD was found to be a past history of TB. In COPD patients, $10 \%$ reported having been diagnosed with pulmonary TB. The overall prevalence of TB in our study was $3.6 \%$ and COPD patients had a 5 -fold increase in TB prevalence (OR 5.93, 95\% CI 2.05-17.18; p<0.001) (table 3). Notably, only $1.7 \%$ of the study subjects (including both COPD and non-COPD subjects) received medication for respiratory complaints. Only one female who had COPD was using an inhaler, while all the other COPD subjects received a single or a combination of oral pills.

\section{Air pollution sampling and monitoring}

The current acceptable $\mathrm{CO}$ concentration level according to the World Health Organization (WHO) is $9 \mathrm{ppm}\left(10 \mathrm{mg} \cdot \mathrm{m}^{-3}\right)$ over an 8 -h period. Our COPD study revealed a mean CO concentration of $>9 \mathrm{ppm}$ in $38 \%$ of the households during cooking hours. Both outdoor and indoor CO concentrations were above the acceptable levels in the majority of households (figure 3). Our study was not powered to examine CO or other measures of biomass fuel exposure as a risk factor for COPD diagnosis. However, these measures provide useful contextual data. The association between indoor and outdoor air pollution and COPD will be discussed in a subsequent article (manuscript in preparation).

\section{Other significant findings}

A restrictive pattern on spirometry was found in $9.8 \%$ of the study participants (40 out of 496 ), specifically among those with a self-reported previous history of TB (11.1\% (two out of 18)). Normal spirometry as defined by $\mathrm{FEV}_{1} / \mathrm{FVC}>0.7$ and FVC $\%$ pred $>80 \%$ was found in $74.4 \%$ (369 out of 496 ) of the study participants.

\section{Discussion}

Our study is the first study performed in Tanzania to report the burden of COPD among males and females in a rural setting. Globally, tobacco smoking is recognised as the major risk factor for developing COPD $[7,23]$. Intriguingly, COPD was noted in a relatively young population together with females who do not smoke due to cultural taboo in Africa, thus highlighting the role of risk factors other than smoking. Currently, there are no reliable figures for smoking prevalence in Tanzania, with most studies citing prevalence of smoking in urban settings $[24,25]$. There are no data on smoking prevalence in rural settings. Our study showed the prevalence of ever-smokers to be $25.2 \%$. The prevalence of current smokers was found to be as low as $5.4 \%$. Although smoking is perceived to be growing rapidly in Tanzania, the studies on smoking prevalence do not seem to reflect this. Our study reports a low prevalence of tobacco smoking. Interestingly, we report that the population-attributable risk for smoking in our population is only $17.02 \%$, which is contrast to the western world. While this may be very region specific, it does support the observation that COPD prevalence is high even in a low-smoking region, suggesting that other non-smoking-related factors may be more important. Air pollution and use of biomass fuel in poorly ventilated households are well-recognised additional risk factors $[9,12,26]$.

In our study, $57.1 \%$ of respondents presented for spirometry, with $>98 \%$ of graphs of acceptable quality. The overall prevalence of COPD was estimated at $17.5 \%(21.7 \%$ in males and $12.90 \%$ in females) based on the post-bronchodilator $\mathrm{FEV} 1 / \mathrm{FVC}<70 \%$ criterion, with males being generally more affected than females. This criterion was adopted for this study despite the existing diagnostic pitfalls for patients aged $<40$ and $>60$ years $[27,28]$. Our findings are in agreement with the existing few studies on COPD conducted in Africa. A review by FinNEY et al. [29] revealed COPD estimates in sub-Saharan Africa to vary between $4 \%$ and $25 \%$ depending on the study population, study design and criteria used for diagnosis. However, as spirometry is rarely used in the majority of COPD studies conducted in Africa, COPD is likely to be grossly underreported [30]. A recent survey in Uganda involving subjects aged $>30$ years revealed a COPD prevalence of $16.2 \%$ (15.4\% in males and $16.8 \%$ in females) based on FEV1/FVC <LLN [2]. Moreover, a global survey by LANDIs et al. [31] showed a comparable COPD prevalence of 7-12\% in a panel of 12 countries. From these findings it is tempting to conclude, contrary to the common assumption, that the prevalence of COPD in Tanzania is higher than in developed countries, but is in accordance with the prevalence reported from other parts of Africa. 


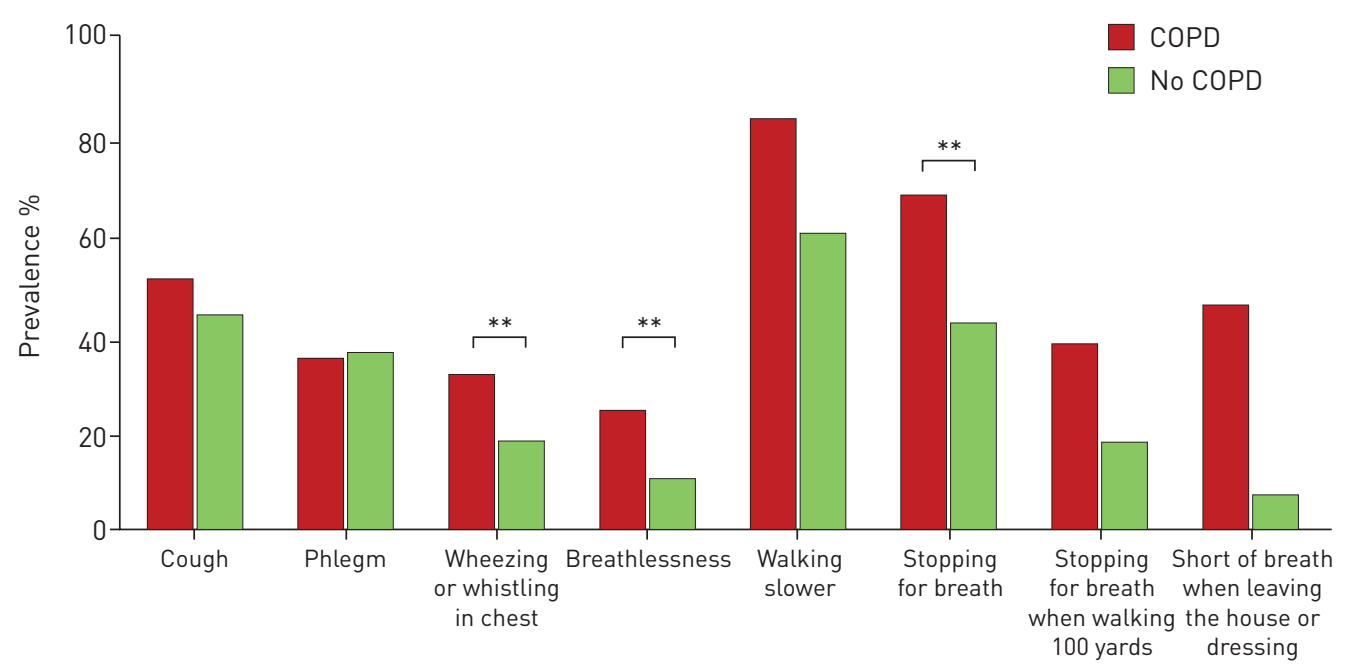

FIGURE 2 Prevalence of respiratory symptoms in patients with and without chronic obstructive pulmonary disease (COPD). 100 yards=91.4 m. ${ }^{* *}: \mathrm{p}<0.01$.

The prevalence of COPD exhibited increased trends with age and male sex in our study, similar to other previous studies [31]. Also similar to previous studies, cigarette smoking was an important risk factor for COPD [2, 23]. The fact that $25.2 \%$ of responders were smokers could partly explain the observed predominance of COPD in males. $42 \%$ of current smokers had significant nicotine dependency, constituting an at-risk population who are not likely to quit smoking and thus are prone to develop COPD.

Apart from tobacco smoking, exposure to indoor biomass smoke and occupational exposures, including farming, are recognised as important risk factors for COPD, especially in developing countries [12]. In our cohort, we did not find any significant association between the prevalence of COPD and the use of biomass fuel for cooking or farming as an occupation. However, this does not mean that indoor biomass smoke and farming were not risk factors for COPD, because in our cohort $99.5 \%$ used biomass fuel for cooking and $96.4 \%$ were involved in farming. There was no power in our study to detect any difference between cases and controls because the control population (not biomass users and not farmers) was too small to detect any differences and identify indoor biomass smoke and farming as risk factors associated with COPD. The mean indoor CO levels were $>2$-fold higher than the WHO safety limit of 9 ppm over

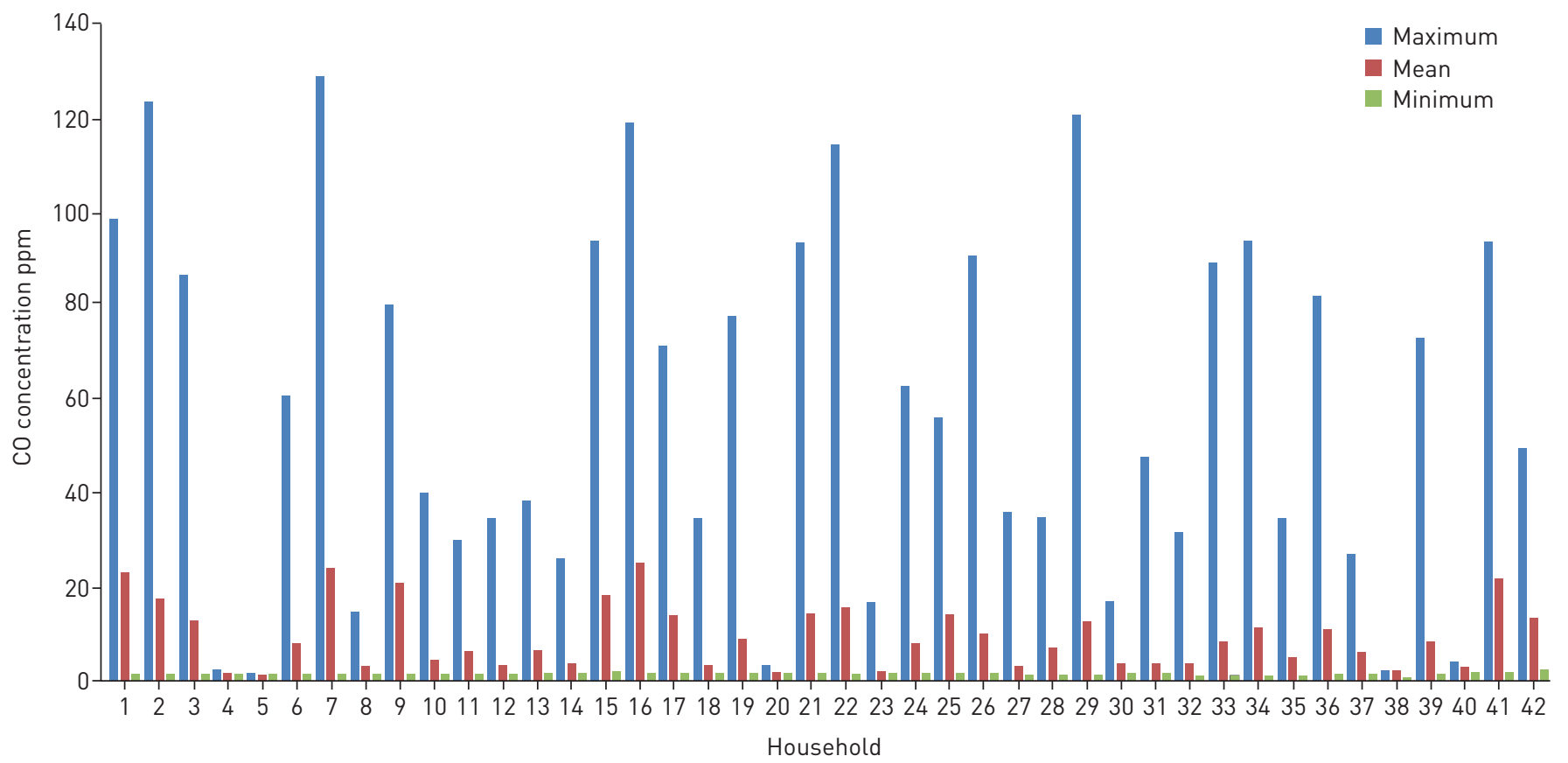

FIGURE 3 Variation of indoor carbon monoxide (CO) concentrations in 42 selected households in Maswa district. 
$8 \mathrm{~h}$, which is in agreement with other studies conducted in Africa [32], and indicates that indoor air pollution due to the burning of biomass fuel may have indeed contributed to the burden of COPD in our population. It is thus evident that control of indoor pollution should be integrated in the intervention packages for COPD in Africa [24, 33]. We could not associate the high levels of indoor air pollution with the type of housing, but we could correlate it with the type of fuel used for cooking and heating. The association between air pollution and COPD has not been detailed in this article; the correlation between air pollution levels and respiratory symptoms and COPD will be discussed in a subsequent article (manuscript in preparation).

Patients with COPD present with a range of respiratory symptoms suggestive of chronic bronchitis and emphysema. In the current study, cough was the major presenting respiratory symptom. In addition, a substantial proportion of females with COPD presented with dyspnoea or shortness of breath and increased frequency of exacerbations, probably indicating severity of disease and a considerably poor quality of life. Dyspnoea has been shown to be a better predictor of survival than airway limitation [34]. The influence of sex on the progression of COPD remains unknown; however, it has been reported recently that females exposed to wood smoke exhibit increased bronchial hyperresponsiveness [35]. Stratification of patients under the GOLD classification did not reveal sex differences, but the majority of patients had mild to moderate airway limitation that was significantly associated with cough, dyspnoea and wheezing. Intriguingly, patients with severe airway limitation were relatively few amid the patients who were found to have spirometrically defined COPD. It remains elusive whether this observation is a result of premature mortality. Interestingly, the study population which did not show airflow limitation on spirometry also had considerable symptoms. $51.7 \%$ of patients with spirometrically defined COPD were found to have cough, $35.6 \%$ had phlegm in the chest which was difficult to bring up, $32.3 \%$ had a wheeze, $25 \%$ reported shortness of breath, $84.6 \%$ reported walking slower than their healthy counterparts, $69.2 \%$ had to stop for breath when walking, $38.5 \%$ had to stop for breath when walking just 100 yards $(91.4 \mathrm{~m})$ and $46.2 \%$ were short of breath when leaving the house or resting. Compared with the population that did not show airflow limitation on spirometry, only wheeze was a symptom significantly associated with COPD, whereas the prevalence of all other symptoms was no different from those subjects who did not have airflow limitation on spirometry. This leads us to conclude that in the rural setting of Tanzania, the common symptoms of COPD are sensitive although not really specific. However, studies have shown that spirometry alone may not be effective in identifying many cases of airflow limitation [36, 37].

Of all assessed comorbidities among COPD patients, 10\% were reported to have a history of pulmonary $\mathrm{TB}$ as opposed to the $2.2 \% \mathrm{~TB}$ found in the non-COPD population; this is increasingly reported as a risk factor for developing COPD [38]. The severe forms and recurrent pulmonary TB cause irreversible airway damage that results in a reduction of pulmonary function and increased risk of developing COPD [39]. However, TB and COPD may coexist in a patient due to shared risk factors, with the presence of active TB exacerbating the underlying subclinical COPD [40]. In our study, the prevalence of self-reported past history of TB was found to be $3.63 \%$. Nine out of 87 COPD patients and nine out of 409 non-COPD participants self-reported a past history of TB, with a 5.93-fold increased risk (OR 5.93, 95\% CI 2.0517.18; $\mathrm{p}<0.001$ ) among COPD subjects. Moreover, the overlap of respiratory symptoms in pulmonary TB and COPD on the background of inadequate expertise and diagnostic tools may result in misdiagnosis and inappropriate management. In our study, we found suboptimal management of patients with COPD, often with less effective drugs, inappropriate routes of drug administration and inadequate duration of treatment. Notably, only $1.7 \%$ of the study subjects (including both COPD and non-COPD subjects) received medication for respiratory complaints. Only one female who had COPD was using an inhaler, whereas all the other COPD subjects received a single or a combination of oral pills. Our study also showed a higher rate of exacerbations and more symptoms in people with mild and moderate disease. It is, however, interesting to note that only two of the 57 male COPD patients and two of the 30 female COPD patients received medication for their disease. This could explain the higher frequency of exacerbations and symptoms even in people with mild and moderate disease. The existing clinical practice exposes patients to suboptimal therapy, adverse effects and poor health-related quality of life. Furthermore, all respondents, including COPD patients, were assessed for additional comorbidities such as heart diseases, heart failure, hypertension, diabetes, lung cancer and stroke.

Our study has some limitations. The high number of nonresponders (43\%) could potentially affect the power of this study. This is also likely to introduce a bias to the study. $43 \%$ of the participants refused to perform spirometry for the following reasons: need for monetary compensation (22\%), local belief and fear of blowing into a spirometer despite repeated reassurances (6\%), absence of symptoms and hence not wanting to perform the test $(7 \%)$, and a feeling of interference with daily routine (8\%). We made every possible attempt to ensure that all participants would attempt spirometry. However, for the aforementioned reasons, not all participants were ready to perform spirometry. While we understand that 
this is a limitation, this is the first study performed in Tanzania to determine the prevalence of COPD in rural Tanzania using post-bronchodilator spirometry.

This was a cross-sectional study that could only identify the prevalence of COPD in the study population at one point in time. It would be worthwhile exploring if people detected with airflow obstruction have a greater risk of disease progression. Hence, there is an urgent need to conduct longitudinal studies to observe the progress of disease to understand any impending risk of disease progression. Similar such studies would be required in this region to gain a better understanding of the disease process in Tanzania.

\section{Conclusions}

This first-ever population-based survey in a predominantly rural setting of Tanzania revealed a high burden of COPD. The study highlighted major challenges in the diagnosis and treatment of patients with COPD, largely due to a lack of disease awareness together with a shortage of expertise and diagnostic tools. These research findings call for an urgent national action plan for the prevention and control of COPD specifically in the rural areas. The intervention package should include cigarette smoking cessation programmes, improvement in the design of cooking stoves and kitchens, use of alternative clean energy together with empowerment of health facilities with skills and capacity for the diagnosis and management of COPD. Furthermore, in order to effectively plan for a comprehensive national COPD intervention package, we recommend additional studies to explore the role of outdoor air pollution resulting from vehicular and industrial emissions on the development of COPD, both in rural as well as urban Tanzania. We acknowledge that these recommendations are based on prior knowledge of risk factors for COPD rather than the results of our study. The current smoking cessation campaign is not very robust and definitely does not percolate into rural Tanzania. Of course smoking intervention is required, but the current smoking rates for adults in our study are lower than in most countries where smoking cessation programmes are well established. Biomass burning is a known risk factor for COPD and interventions are important, but our study was not designed to provide compelling evidence for an association between biomass burning and COPD prevalence.

\section{Acknowledgement}

This study was conducted by Ifakara Health Institute (Dar es Salaam, Tanzania) in collaboration with local and international investigators. We greatly acknowledge the BOLD Centre (Imperial College London, London, UK) for providing the protocol used in this study. We thank all research assistants together with the administrative and health authorities in Maswa district. We are greatly indebted to all study participants.

Author contributions: N.F. Magitta conceived and designed the study. The draft of the study was reviewed by R.W. Walker, M.D. Shimwela, J.D. Mwaiselage, A.K. Namdeo and S.S. Salvi. N.F. Magitta, M.D. Shimwela, J.D. Mwaiselage, A.K. Namdeo and A.A. Sanga trained the research assistants. A.A. Sanga performed spirometry and supervised data entry. S.S. Salvi, K.K. Apte and S.J. Madas analysed data and performed statistical analysis. N.F. Magitta prepared the results and wrote the first draft of the manuscript. N.F. Magitta, R.W. Walker, K.K. Apte, S.J. Madas and S.S. Salvi wrote the revised draft. All investigators reviewed the final version of the manuscript.

\section{References}

1 Global Burden of Disease Study 2013 Collaborators. Global, regional, and national incidence, prevalence, and years lived with disability for 301 acute and chronic diseases and injuries in 188 countries, 1990-2013: a systematic analysis for the Global Burden of Disease Study 2013. Lancet 2015; 386: 743-800.

2 van Gemert F, Kirenga B, Chavannes N, et al. Prevalence of chronic obstructive pulmonary disease and associated risk factors in Uganda (FRESH AIR Uganda): a prospective cross-sectional observational study. Lancet Glob Health 2015; 3: e44-e51.

3 Teo WS, Tan WS, Chong WF, et al. Economic burden of chronic obstructive pulmonary disease. Respirology 2012; 17: 120-126.

$4 \quad$ Salvi S. The silent epidemic of COPD in Africa. Lancet Glob Health 2015; 3: e6-e7.

5 Kirilloff LH, Carpenter V, Kerby GR, et al. Skills of the health team involved in out-of-hospital care for patients with COPD. Am Rev Respir Dis 1986; 133: 948-949.

6 Stockley RA, Mannino D, Barnes PJ. Burden and pathogenesis of chronic obstructive pulmonary disease. Proc Am Thorac Soc 2009; 6: 524-526.

7 Viegi G, Pedreschi M, Pistelli F, et al. Prevalence of airways obstruction in a general population: European Respiratory Society vs American Thoracic Society definition. Chest 2000; 117: 5 Suppl. 2, 339S-345S.

8 Fullerton DG, Gordon SB, Calverley PM. Chronic obstructive pulmonary disease in non-smokers. Lancet 2009; 374: 1964-1966.

9 Hopkinson NS, Polkey MI. Chronic obstructive pulmonary disease in non-smokers. Lancet 2009; 374: 1964-1966.

10 Nguyen Viet N, Yunus F, Nguyen Thi Phuong A, et al. The prevalence and patient characteristics of chronic obstructive pulmonary disease in non-smokers in Vietnam and Indonesia: an observational survey. Respirology 2015; 20: 602-611.

11 Pavord ID, Yousaf N, Birring SS. Chronic obstructive pulmonary disease in non-smokers. Lancet 2009; 374: 1964-1966.

12 Salvi SS, Barnes PJ. Chronic obstructive pulmonary disease in non-smokers. Lancet 2009; 374: 733-743.

13 Sexton P, Black P, Wu L, et al. Chronic obstructive pulmonary disease in non-smokers: a case-comparison study. COPD 2014; 11: 2-9. 
14 Rylance J, Fullerton DG, Semple S, et al. The global burden of air pollution on mortality: the need to include exposure to household biomass fuel-derived particulates. Environ Health Perspect 2010; 118: A424.

15 Kiraz K, Kart L, Demir R, et al. Chronic pulmonary disease in rural women exposed to biomass fumes. Clin Invest Med 2003; 26: 243-248.

16 Salvi D, Limaye S, Muralidharan V, et al. Indoor particulate matter $<2.5 \mu \mathrm{m}$ in mean aerodynamic diameter and carbon monoxide levels during the burning of mosquito coils and their association with respiratory health. Chest 2016; 149: 459-466.

17 Fabbri L, Caramori G, Beghe B, et al. Chronic obstructive pulmonary disease international guidelines. Curr Opin Pulm Med 1998; 4: 76-84.

18 Steinacher R, Parissis JT, Strohmer B, et al. Comparison between ATS/ERS age- and gender-adjusted criteria and GOLD criteria for the detection of irreversible airway obstruction in chronic heart failure. Clin Res Cardiol 2012; 101: 637-645.

19 Chan-Yeung M, Aït-Khaled N, White N, et al. Management of chronic obstructive pulmonary disease in Asia and Africa. Int J Tuberc Lung Dis 2004; 8: 159-170.

20 Abdool-Gaffar MS, Ambaram A, Ainslie GM, et al. Guideline for the management of chronic obstructive pulmonary disease - 2011 update. S Afr Med J 2011; 101: 63-73.

21 Bateman ED, Feldman C, O'Brien J, et al. Guideline for the management of chronic obstructive pulmonary disease (COPD): 2004 revision. S Afr Med J 2004; 94: 559-575.

22 Fullerton DG, Suseno A, Semple S, et al. Wood smoke exposure, poverty and impaired lung function in Malawian adults. Int J Tuberc Lung Dis 2011; 15: 391-398.

23 American Thoracic Society. Cigarette smoking and health. Am J Respir Crit Care Med 1996; 153: 861-865.

24 Jagoe K, Edwards R, Mugusi F, et al. Tobacco smoking in Tanzania, East Africa: population based smoking prevalence using expired alveolar carbon monoxide as a validation tool. Tobacco Control 2002; 11: 210-214.

25 Bovet P, Ross GA, Gervasoni J-P, et al. Distribution of blood pressure, body mass index and smoking habits in the urban population of Dar es Salaam, Tanzania, and associations with socioeconomic status. Int J Epidemiol 2002; 31: $240-247$

26 Fullerton DG, Bruce N, Gordon SB. Indoor air pollution from biomass fuel smoke is a major health concern in the developing world. Trans R Soc Trop Med Hyg 2008; 102: 843-851.

27 Hnizdo E, Glindmeyer HW, Petsonk EL, et al. Case definitions for chronic obstructive pulmonary disease. COPD 2006; 3: 95-100.

28 Vollmer WM, Gíslason T, Burney P, et al. Comparison of spirometry criteria for the diagnosis of COPD: results from the BOLD study. Eur Respir J 2009; 34: 588-597.

29 Finney LJ, Feary JR, Leonardi-Bee J, et al. Chronic obstructive pulmonary disease in sub-Saharan Africa: a systematic review. Int J Tuberc Lung Dis 2013; 17: 583-589.

30 Mehrotra A, Oluwole AM, Gordon SB. The burden of COPD in Africa: a literature review and prospective survey of the availability of spirometry for COPD diagnosis in Africa. Trop Med Int Health 2009; 14: 840-848.

31 Landis SH, Muellerova H, Mannino DM, et al. Continuing to Confront COPD International Patient Survey: methods, COPD prevalence, and disease burden in 2012-2013. Int J Chron Obstruct Pulmon Dis 2014; 9: 597-611.

32 Fullerton DG, Semple S, Kalambo F, et al. Biomass fuel use and indoor air pollution in homes in Malawi. Occup Environ Med 2009; 66: 777-783.

33 Fullerton DG, Semple S. Air pollution and health: indoor air pollution in the developing world is the real key to reducing the burden of ill health. Thorax 2008; 63: 288 .

34 Nishimura K, Izumi T, Tsukino $\mathrm{M}$, et al. Dyspnea is a better predictor of 5-year survival than airway obstruction in patients with COPD. Chest 2002; 121: 1434-1440.

35 Gonzalez-Garcia M, Torres-Duque CA, Bustos A, et al. Bronchial hyperresponsiveness in women with chronic obstructive pulmonary disease related to wood smoke. Int J Chron Obstruct Pulmon Dis 2013; 7: 367-373.

36 Jamaati HR, Heshmat B, Tamadon R, et al. Association between severity of chronic obstructive pulmonary disease and lung function tests. Tanaffos 2013; 12: 36-41.

37 Hajiro T, Nishimura K, Tsukino M, et al. A comparison of the level of dyspnea vs disease severity in indicating the health-related quality of life of patients with COPD. Chest 1999; 116: 1632-1637.

38 van Zyl Smit RN, Pai M, Yew WW, et al. Global lung health: the colliding epidemics of tuberculosis, tobacco smoking, HIV and COPD. Eur Respir J 2010; 35: 27-33.

39 Hnizdo E, Singh T, Churchyard G. Chronic pulmonary function impairment caused by initial and recurrent pulmonary tuberculosis following treatment. Thorax 2000; 55: 32-38.

40 Chakrabarti B, Calverley PM, Davies PD. Tuberculosis and its incidence, special nature, and relationship with chronic obstructive pulmonary disease. Int J Chron Obstruct Pulmon Dis 2007; 2: 263-272. 